\title{
Ruptura y CONTINUIDAD. ORIGEN Y EVOLUCIÓN DE LOS ESPACIOS FUNERARIOS MEDIEVALES EN EL SUR DE CANTABRIA
}

\section{Rupture and continuity. Origin and evolution of the medieval funerary spaces in the south of Cantabria}

\author{
ENRIQUe GuTIÉRREZ CUENCA \\ Proyecto Mauranus
}

Recibido: 04/04/2019

Revisado: 22/04/2019
Aceptado: 29/05/2019

Publicado: 05/07/2019

\section{RESUMEN}

Este trabajo recoge un estudio actualizado de algunos aspectos de tres necrópolis del sur de Cantabria con orígenes anteriores al siglo VIII. Se presta atención a los procesos de ruptura y continuidad que refleja el registro arqueológico de los espacios funerarios en el tránsito entre la Antigüedad y la Edad Media y a lo largo de los siglos medievales.

\section{Palabras clave}

Necrópolis; Sepultura; Antigüedad Tardía; Edad Media; Continuidad; Ruptura.

\section{ABSTRACT}

This work includes an updated study of some aspects of three cemeteries in southern Cantabria with origins before the eighth century. Attention is paid to the processes of rupture and continuity that reflect the archaeological record of the funerary spaces in the transit between Antiquity and the Middle Ages and throughout the medieval centuries.

\section{KEYWORDS}

Cemetery; Burial; Late Antiquity; Middle Ages; Continuity; Rupture.

egcuenca@gmail.com 


\section{INTRODUCCIÓN}

El objeto de este trabajo es analizar los procesos de ruptura y continuidad que se perciben a través del estudio de los espacios funerarios en el tránsito entre la Antigüedad y la Edad Media en el ámbito rural, así como esbozar su desarrollo en los siglos medievales, una vez convertidos en cementerios. Para ello nos vamos a servir de los datos proporcionados por las tres necrópolis mejor conocidas del sur de Cantabria en uso antes del siglo VIII (figura 1): Santa María de Retortillo (Enmedio), El Conventón de Rebolledo (Valdeolea) y Santa María de Hito (Valderredible). Hemos tenido oportunidad de revisar la información proporcionada por las diferentes excavaciones realizadas en los distintos yacimientos desde 1940 hasta fechas recientes, y de ofrecer una visión de conjunto en nuestra tesis doctoral (Gutiérrez Cuenca, 2015). Una parte importante de los datos que manejamos proceden de actuaciones arqueológicas antiguas y muchos permanecían inéditos, tanto memorias y material gráfico como colecciones de museo, especialmente en el caso de Santa María de Hito1.

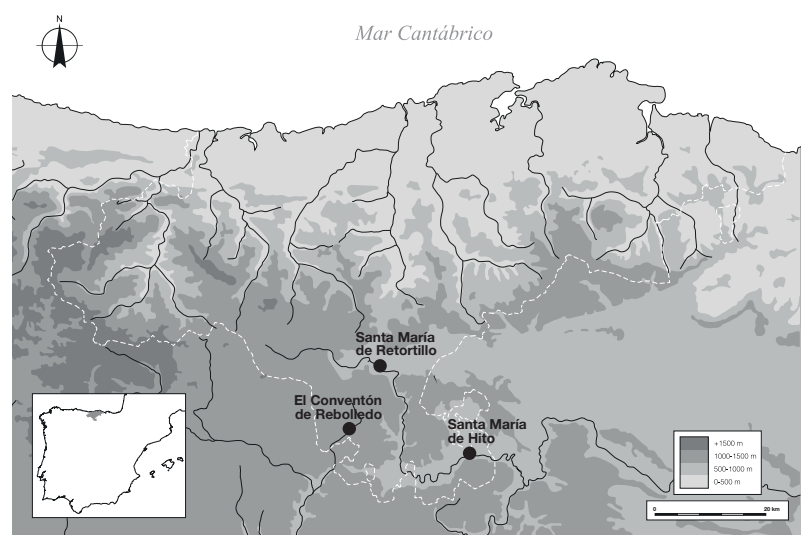

Fig. 1. Situación de las necrópolis mencionadas en el texto. Mapa: E. Gutiérrez Cuenca.

El registro arqueológico permite apreciar una ruptura funcional con respecto a la época romana, pero hay algunos elementos que sugieren una voluntad bastante evidente de mantener un vínculo con el pasado. Menos evidentes son los motivos de

1 Agradecemos a Rosa Gimeno García-Lomas, directora de la excavación realizada en Santa María de Hito entre 1979 y 1986 la cesión de toda la documentación recogida durante la actuación arqueológica. Miguel Ángel García Guinea nos facilitó el acceso a la documentación disponible en el Instituto Sautuola sobre las campañas realizadas en El Conventón de Rebolledo entre 1981 y 1986. este comportamiento, que pueden ser meramente utilitarios o estar ligados con ideas más abstractas como la apropiación simbólica del pasado.

La pauta de continuidad se hace evidente una vez que se crea el espacio funerario, común hasta los primeros siglos de la Edad Media, pero que se perpetuará o se interrumpirá como consecuencia de dinámicas propias en las que influyen decisivamente agentes externos, sobre todo una Iglesia cada vez más y mejor organizada desde el punto de vista territorial.

La revisión de los datos procedentes de estas excavaciones antiguas permite comprender mejor los procesos históricos que reflejan los espacios funerarios, cuyos restos materiales son la principal fuente para conocer esta época de cambio.

\section{BREVE RESEÑA HISTORIOGRÁfICA}

El interés de J. Carballo por sacar a la luz los restos arqueológicos en la aldea de Retortillo, el lugar en el que E. Flórez había identificado en el siglo XVIII la Iuliobriga de las fuentes clásicas permitió llevar a cabo en 1940 la primera excavación en la que se identifican con claridad sepulturas anteriores al siglo VIII en Cantabria. Mucho más curtido como prehistoriador, las limitaciones de J. Carballo en el ámbito de la Arqueología de época histórica eran bastante evidentes y estaban en consonancia con la imprecisión con la que se interpretaban en clave regional los espacios funerarios exhumados durante las últimas décadas del siglo XIX y las primeras del XX. Lugares como la necrópolis de Espinilla, en la que A. de los Ríos realizó destacados hallazgos entre 1865 y 1892 (Gutiérrez Cuenca, 2015, 159-165) o las de San Pedro de Solía (Carballo, 1909) y San Salvador (Carballo, 1910), que hoy consideramos de época medieval, eran tenidos entonces por los cementerios de los antiguos Cántabros de la Edad del Hierro. En el caso de Santa María de Retortillo la adscripción cronológica fue más certera. La posición estratigráfica de las tumbas -superpuestas a las ruinas romanas- junto con el hallazgo de una estela con la inscripción TEVDE/S( $i) \mathrm{NDE}$-antropónimo que J. Carballo considera germánico- y de un broche de cinturón liriforme son argumentos de peso para relacionar las tumbas con las invasiones bárbaras de los siglos V-VI. También es consecuencia de esas invasiones, a juicio de J. Carballo, la destrucción de la ciudad romana, materializada en una espesa capa de carbones sobre la que se disponen las tumbas. Sobre la identidad de los invasores, su hipótesis es que podría tratarse de suevos (Carballo, 1941). Sin embargo, 
no usará como paralelos las grandes necrópolis visigodas que se están excavando en la Meseta en esa época, sino que recurre a una experiencia personal mucho más cercana: los hallazgos que realizó en la cueva de Los Hornucos de Suano unos años antes (Carballo, 1935). A pesar de ser desde 1926 director del Museo de Prehistoria de Santander, su actividad arqueológica se asimilaba más a la que se practicaba fuera de las instituciones, con evidente desconocimiento de lo que sucede fuera de Cantabria y un tanto al margen de las corrientes historiográficas vigentes, más allá del apunte etnicista de rigor.

Cuando, a comienzos de la década de 1980, los espacios funerarios altomedievales vuelven a tener protagonismo en la Arqueología de Cantabria, encontraremos un panorama un tanto diferente. Lejos de los planteamientos de J. Carballo, en los que subyacía una cierta "inocencia", nos encontraremos con un escenario en el que un discurso histórico concreto, establecido previamente, será el marco en el que tengan que encajar los datos arqueológicos. Unas tesis asentadas en tres pilares: indigenismo, la vuelta a la Edad del Hierro en lo económico, lo social y lo político durante los siglos que van desde la crisis del mundo romano a la invasión musulmana, siguiendo el modelo de Barbero y Vigil (1974); Repoblación como modelo explicativo fundamental en los movimientos sociales y culturales de la Alta Edad Media; y "epivisigotismo" como explicación para la presencia de objetos de tipología hispanovisigoda al norte de la cordillera Cantábrica como consecuencia de los movimientos de población provocados por la invasión musulmana a partir de 711 (Van den Eynde, 1986). El mejor ejemplo lo encontramos aplicado al caso de El Conventón de Rebolledo, donde a pesar de las evidencias disponibles se evita en todo momento, por ejemplo, hablar de una fase de época visigoda. Incluso disponiendo ya de dataciones de ${ }^{14} \mathrm{C}$ del siglo VII para las tumbas de los primeros momentos de uso de la necrópolis en un primer momento, las fechas manejadas sin calibrar se atribuyen a momentos más antiguos, en torno al 585-, se habla de "grupos tardorromanos" de fuerte sustrato indígena para los que se niega de forma explícita cualquier conexión con las "comunidades germánicas” instaladas en la zona de la Meseta (García Guinea y Van den Eynde, 1991).

Para el periodo anterior al siglo VIII E. Van den Eynde $(1985,285)$ habla de la pervivencia de ritos paganos de la «ausencia de necrópolis visigóticas» en incluso rechaza frontalmente las propuestas de otros investigadores con menos prejuicios en el análisis del registro arqueológico, como sucede con el posicionamiento de A. Besga sobre la necrópolis de Iuliobriga. Este investigador hace un planteamiento diferente sobre los siglos de transición entre la Antigüedad y la Edad Media (Besga, 1983) que será ignorado por la historiografía local, que siguió aferrada al paradigma dominante, llegando a publicar los resultados de las excavaciones realizadas en El Conventón casi dos décadas después ignorando por completo los debates abiertos sobre un periodo en continua discusión (Van den Eynde, 2002).

Negado cualquier atisbo de "visigot is mo", incluso con vehemencia (García Guinea, 1999), se descarta también cualquier posible continuidad, aferrándose a la idea de atribuir la "eclosión" de las necrópolis cristianas a partir del siglo VIII a la masiva llegada de inmigrantes desde el S tras la invasión de 711 propuesta por E. Van den Eynde (1985).

Sin embargo, los estudios realizados en las últimas décadas no identifican la existencia de unas prácticas funerarias en Cantabria que se pueden considerar originales, diferentes y ajenas por completo a las que se distinguen en la Tardoantigüedad y la Alta Edad Media en otros territorios de la península Ibérica que, en conjunto y dentro de su variabilidad (Azkarate, 2002), mantienen unas ciertas características comunes. Este particularismo sería lo esperable si realmente estuviésemos ante comunidades con una organización social y una religiosidad peculiar, diferenciadas del entorno. Más bien al contrario, tanto la revisión de las excavaciones antiguas como las nuevas actuaciones llevadas a cabo redundan en la semejanza apreciable entre las practicas funerarias identificadas en Cantabria y las que se conocen en otros territorios del reino visigodo de Toledo entre los siglos VI y VIII, tanto en lo que se refiere a las necrópolis (Gutiérrez y Hierro, 2015) como para el uso de las cuevas (Gutiérrez y Hierro, 2012; Arias et al., 2017). En este mismo sentido vamos a seguir profundizando con este trabajo, puesto que son mucho más evidentes los indicios que sugieren la integración efectiva de todo el territorio de Cantabria en la órbita económica, social y seguramente política de la monarquía visigoda que los que inducen a pensar lo contrario. Por otra parte, del registro arqueológico también sugiere una continuidad entre los espacios funerarios de época visigoda y los cementerios medievales en una lectura de larga duración, tendencia que tiene más peso incluso que los cambios que se aprecian en torno al siglo VIII. 


\section{LA RUPTURA CON EL MUNDO ROMANO: DE HÁBITAT} A ESPACIO FUNERARIO

Una característica común a los espacios funerarios que se empiezan a utilizar antes del siglo VIII en Cantabria es que se establecen sobre estructuras de época romana ${ }^{2}$.

En términos de articulación del territorio a escala regional debemos entender esa vinculación como una permanencia en la distribución del poblamiento, teniendo en cuenta que es precisamente el sur de Cantabria la zona con mayor presencia en época romana y en la que también se concentran una parte importante de evidencias materiales de época visigoda. A partir del siglo VI se seguirán frecuentando los mismos lugares, pero se produce una modificación sustancial en la función de los enclaves que vemos plasmada en el radical cambio de uso que experimentan los edificios. Es en este proceso de cambio de funcionalidad en el que se detecta la ruptura más evidente. Lo que antes eran estructuras de hábitat, se convierten en espacios específicamente funerarios y, como veremos más adelante, es un cambio de uso irreversible y que se consolidará en el tiempo.

No sabemos qué sucede con los espacios funerarios romanos, si se abandonan o se convierten en un polo de atracción de sepulturas como sucede en otros ámbitos. Las carencias de la documentación arqueológica impiden que podamos aportar algo en este terreno. Lo mismo ocurre con la relación entre los espacios funerarios y los espacios de hábitat, desconocidos estos últimos a partir del siglo $\mathrm{V}$.

Es difícil determinar la relación efectiva entre los usuarios de estos espacios a lo largo del tiempo, ya que solo en Santa María de Hito se podría defender una apropiación por continuidad, en la que los campesinos vinculados a una villa en uso, al menos, hasta el siglo $\mathrm{V}$, pudieran ser los mismos que unas generaciones después utilicen sus ruinas como espacio funerario en la etapa posterior. También está abierta la posibilidad de una donación por parte de

2 Esto no quiere decir que la reocupación de edificios romanos con función funeraria tenga que estar ligada necesariamente con la configuración de espacios funerarios "tempranos". Tenemos un buen ejemplo en San Juan de Maliaño (Camargo), donde la ocupación de unas termas por un cementerio medieval dispuesto en torno a una iglesia románica no parece remontarse más allá del siglo XII (Gutiérrez Cuenca, 2015, 433-434). También se aprecia un cierto hiato en la Abadía de los Cuerpos Santos de Santander, lo que puede estar indicando que el modelo sea diferente en la costa. los possessores a la Iglesia ${ }^{3}$. Tanto en El Conventón de Rebolledo como en Santa María de Retortillo el periodo que transcurre desde su abandono en época romana -que se produce en torno al siglo III- hasta su reocupación como necrópolis en el siglo VI es demasiado largo como para identificar una relación de continuidad evidente entre antiguos propietarios y nuevos usuarios.

En los tres lugares que estamos analizando en este trabajo se produce una reocupación de las estructuras romanas en diversos grados que van desde una estrecha relación con zonas del edificio que posiblemente estaban aún en pie o eran muy visibles, como sucede en El Conventón, hasta una ocupación más difusa de espacios públicos que tuvieron en origen carácter urbano, como es el caso de Retortillo.

El caso de El Conventón de Rebolledo (figura 2) es, sin duda, el más interesante por la evidente intencionalidad en el aprovechamiento de la arquitectura preexistente. La necrópolis se instala sobre diferentes estancias de un edificio de época romana abandonado en torno al siglo III, las mejor conservadas de las cuales forman parte de un pequeño complejo termal. Por el momento el edificio principal es el único en el que se documentan sepulturas y solo aparecen fuera del recinto en la zona E, sin que en el resto de edificios identificados en el entorno se hayan detectado evidencias claras de uso sepulcral.

La estrecha y evidente relación entre la disposición del edificio romano y la de algunas de las sepulturas superpuestas ya llamó la atención de quienes excavaron el yacimiento en la década de 1980 (Van den Eynde e Illarregui, 1986). Estos investigadores consideraron el yacimiento como un ejemplo de integración de una necrópolis sobre una estructura romana a partir de diversos argumentos: las tumbas se disponen buscando los espacios libres del edificio evitando destruir cimentaciones, disposición que solo consideran posible si las estructuras de época romana eran aún visibles; las fosas de las sepulturas rompen el pavimento romano, lo que indicaría que sobre el suelo no hay una capa de tierra lo suficientemente potente; además, hay una estructura,

3 Esta posibilidad ha sido sugerida durante el Congreso Internacional In Rure 2017. El mundo de la muerte. Evolución y prácticas funerarias en el Mundo Antiguo y la Edad Media por R. Cebrián Fernández (UCM). Enlazaría con la idea de la presencia de jerarquías religiosas vinculadas a ciertos objetos de prestigio presentes en la necrópolis en el siglo VII, planteada previamente (Gutiérrez y Hierro, 2009). 
identificada como "osario" (figura 2: 1), que ha sido construida aprovechando un muro romano que tenía que quedar a la vista hasta cierta altura. El resultado de la utilización de los espacios del edificio romano -que califican de "aparentemente caótica" frente a la ordenación más regular de las tumbas de la fase altomedieval- le confiere al conjunto funerario un aspecto singular en el que la orientación de las sepulturas parece tener una importancia secundaria.

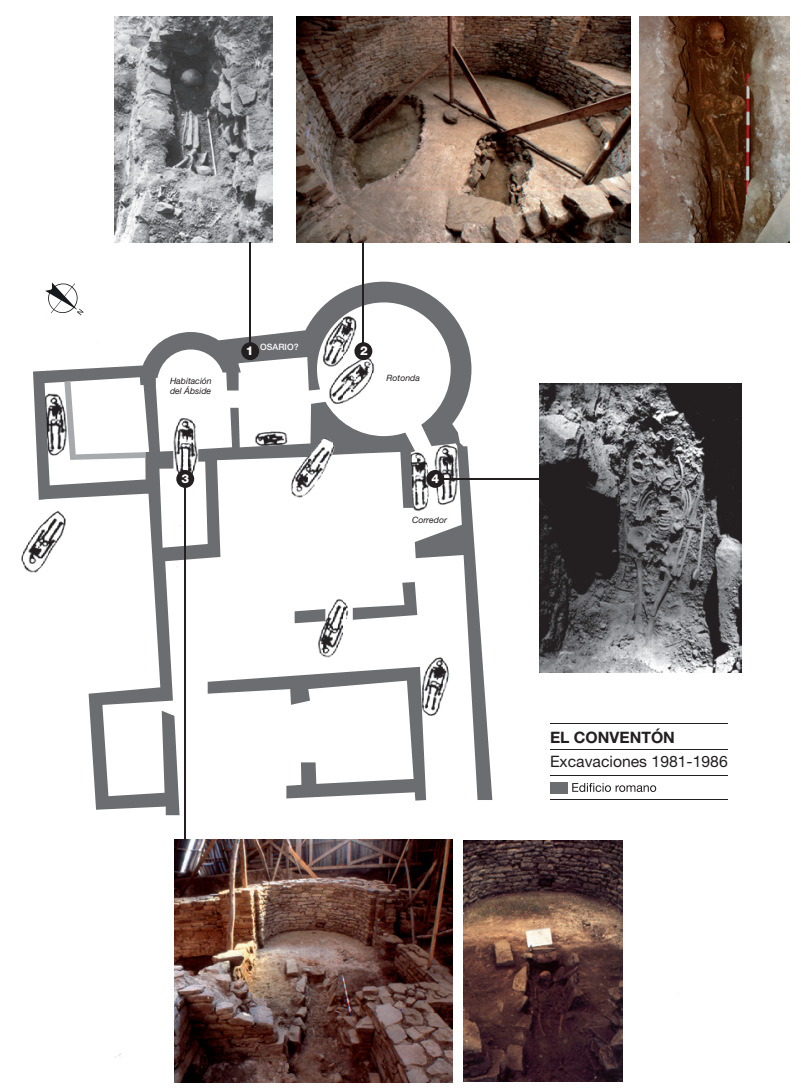

Fig. 2. Sepulturas con disposición adaptada a la distribución del edificio romano de El Conventón. Plano: Van den Eynde e Illarregui, 1986 (modificado). Fotos: Archivo Instituto Sautuola.

Desde nuestro punto de vista, la relación entre estructuras y sepulturas, al menos en el sector W del edificio de época romana, es incluso más estrecha de lo que supusieron E. Van den Eynde y E. Illarregui. Todo parece indicar que se trata de una reutilización intencionada de las estructuras arquitectónicas para crear un espacio funerario segmentado dentro del edificio, cuando los muros de época romana aún eran visibles, conformando un conjunto que se asemeja a un mausoleo. Al menos cinco sepulturas de las documentadas en la década de 1980 recibieron un tratamiento particular y fueron colocadas en lugares muy concretos de un edificio que muy probablemente seguía en pie en el momento en el que fue utilizado con fines funerarios, en torno al siglo VII: dos sepulturas de individuos adultos depositadas en sendas fosas excavadas en el pavimento de la Rotonda (figura 2: 2), una de ellas con los huesos removidos; una sepultura de un individuo adulto colocada en el paso a la Habitación del Ábside (figura 2: 3), cuya fosa aparentemente también rompe el suelo romano; y dos sepulturas de adultos dispuestas en el Corredor de acceso a la Rotonda (figura 2: 4), con la fosa peor delimitada que las anteriores. En estos tres casos, sobre todo en los dos primeros, parece evidente la intencionalidad del lugar elegido y todo indica que era un lugar cerrado, con los muros a la vista, y, aunque la disposición de las estructuras ha condicionado la orientación, en términos generales se colocan hacia el E, dentro de un rango amplio desde NEE hasta SE. Otro elemento del complejo funerario lo constituiría la estancia denominada Habitación 1, en la que se construyó una estructura en la que aparecen restos humanos ${ }^{4}$ aprovechando el grueso muro de cierre y que acoge, al menos una sepultura infantil -quizá una que aparece cubierta con un ímbrice romano, pero no está claro- junto al otro muro. Es posible que la Habitación 2, en la que se han documentado varias sepulturas, de las cuales las más profundas fueron colocadas en paralelo a los muros de la estancia, forme parte también del espacio con estructuras visibles aprovechado como recinto funerario en época visigoda. En ninguna de las sepulturas se han localizado elementos de ajuar o de adorno personal y únicamente contamos con una datación de ${ }^{14} \mathrm{C}$ para uno de los individuos de la Rotonda, fechado en torno a mediados del siglo VII cal AD.

También las cuatro sepulturas localizadas en una estancia ubicada al E del complejo termal -excava-

4 En las memorias de la excavación se denomina "osario" y aparece descrita como una estructura construida "aprovechando la pared romana y ensanchándola con murete bien claramente diferenciado, por la utilización de argamasa abundante y blanca" y en cuyo interior había restos humanos "quedando mezclados en él cabezas y fémures de al menos dos muertos con los cráneos a uno y otro lado de la caja de piedras, por lo que la orientación era de N. a S." (García Guinea, 1985, 214). A falta de datos más precisos no podemos determinar con seguridad de si se trata un depósito secundario, con restos procedentes del vaciado de sepulturas, o de una sepultura colectiva semejante a las identificadas en Valencia (Alapont y Ribera, 2006). 
das tras la reactivación de las actuaciones arqueológicas en el yacimiento a partir de 2003 bajo la dirección de P. A. Fernández Vega- se acomodan a la ordenación del edificio romano. El conjunto, formado por tres sepulturas de adulto - una de ellas fechada en torno a la segunda mitad del siglo VI cal AD- y una infantil, se puede interpretar como un recinto funerario (figura 3 ).

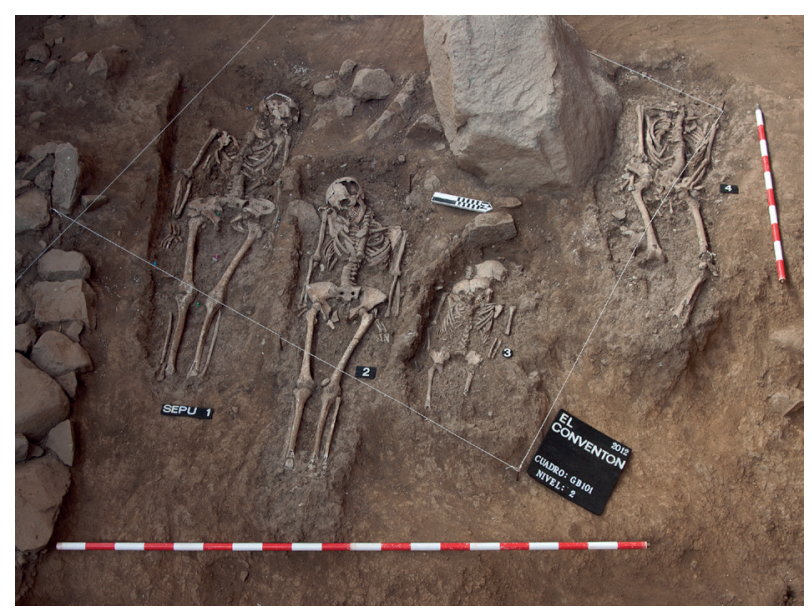

Fig. 3. Sepulturas de El Conventón. Foto: L. Mantecón Callejo.

Existen algunos indicios del uso de edificios romanos todavía en pie con fines funerarios durante la Antigüedad Tardía en otras zonas de la península Ibérica, aunque no es un aspecto al que se le haya prestado especial interés en la investigación. Quizá el más destacable sea el del edificio residencial de la villa de Baños de la Reina (Calpe, Alicante), donde se ha podido comprobar que algunas de las tumbas se instalaron "con parte de la estructura aún en pie" (Abascal et al., 2008). En la villa romana del Torrexón de Veranes (Asturias) también se utilizan para colocar sepulturas estructuras del edificio aún en pie, algunas de ellas transformadas en un edificio de culto cristiano (Fernández y Gil, 2007). También encontramos semejanzas con el mausoleo de La Torrecilla (Corella, Navarra), construido en el siglo IV, que tiene seis exedras similares a la Rotonda de El Conventón. Al menos dos de las exedras fueron ocupadas por enterramientos infantiles en época visigoda, cuando el edificio aún estaba en pie y se reaprovecha, posiblemente, con función de capilla en torno a la que se disponen varios enterramientos (Bienes, 2007), aunque en este caso se reaprovecha un edificio de uso funerario y no de hábitat.
La repetida ocupación de edificios de época romana con fines sepulcrales, tan frecuente en las zonas rurales del occidente europeo (Chavarría, 2007, 134-137), permite afirmar que nos encontramos ante una vinculación intencionada de los nuevos espacios funerarios con los edificios romanos. Ya sea interpretado en términos de apropiación efectiva del territorio, o desde el punto de vista del valor simbólico o identitario de un pasado más o menos remoto, lo que está claro es que la ruptura funcional es evidente. Y el papel de las estructuras arquitectónicas bien conservadas apunta en muchos casos a una indudable intención utilitaria, aprovechando las edificaciones para configurar diferentes espacios dentro del conjunto funerario, como señala J. Pinar (2007).

Independientemente del modelo de reocupación que se practique sobre las estructuras romanas, lo más significativo es que en la mayor parte de los casos se produce una amortización de espacios de hábitat para su empleo como espacios funerarios que, como sucede en Cantabria, perpetuarán a largo plazo esta nueva función.

\section{LOS ESPACIOS FUNERARIOS EN ÉPOCA VISIGODA}

La caracterización de las necrópolis de época visigoda en Cantabria ya ha sido abordada con anterioridad de forma más o menos detallada (Gutiérrez y Hierro, 2007 y 2015; Gutiérrez Cuenca, 2015). Nos vamos a detener aquí en discutir únicamente algunos aspectos concretos referidos a la cronología, a las tipologías funerarias y a los ajuares que acompañan a las sepulturas, cuestiones que resultan de interés para comprender mejor el funcionamiento de los espacios funerarios y los procesos en los que tienen protagonismo.

Las dataciones absolutas han jugado un papel clave en el establecimiento de la cronología de los espacios funerarios del sur de Cantabria. Esto ha estado motivado por diversos factores. Por un lado, por la ausencia o escasez de otros elementos diagnósticos, sobre todo la poca frecuencia con la que aparecen objetos acompañando a las sepulturas o su propia indefinición, como sucede con los anillos. Es muy significativo en este sentido el caso de El Conventón, donde los elementos más característicos -un hebijón de base escutiforme, un fragmento de un broche de placa rígida- aparecen fuera de contexto, disociados de las sepulturas a las que probablemente pertenecieron. Por otro lado, también existe una indefinición en la seriación de 
las tipologías sepulcrales A pesar de contar con secuencias estratigráficas, la imprecisión cronológica también alcanza a las etapas posteriores, para las que también ha sido clave el recurso a la cronología absoluta (Gutiérrez Cuenca, 2002, 100-102), lo que añade más incertidumbre en este asunto. Lo único que estaba bastante claro era que había fases antiguas -anteriores a las necrópolis medievales clásicas- y ya hemos visto más arriba los problemas de interpretación que ello suscitaba en el paradigma dominante.

Las primeras dataciones obtenidas en la década de 1980 para El Conventón (GrN-13770: 1365 30 BP) y Santa María de Hito (CSIC-838: 1430 \pm 40 BP) fueron de gran importancia para fijar la cronología de esas fases antiguas, pero no permitían ir más atrás del siglo VII cal $\mathrm{AD}$, un margen escaso si tenemos en cuenta el número de sepulturas que se concentrarían en un estrecho lapso en algunas necrópolis. Ha sido en momentos más recientes cuando se han podido llevar hasta el siglo VI cal AD los episodios más antiguos de uso funerario en Santa María de Retortillo (GrN-26982: 1540 \pm 30 BP) y El Conventón (Poz-32922: 1490ะ30 BP). El recurso al radiocarbono sigue siendo una herramienta clave a partir de la que se pueden construir esquemas más fiables, basados en datos objetivos, sobre todo ante la ausencia de otros referentes. Las dataciones permiten establecer hitos en las secuencias y contribuyen en gran medida a comprender el desarrollo diacrónico de conjuntos complejos como los que aquí se estudian.

Por lo que respecta al tipo de contenedor empleado para las sepulturas, en todas las necrópolis del sur de Cantabria encontramos la variabilidad propia del periodo tardoantiguo (Ripoll, 1996). La sepultura en fosa simple es el modelo más frecuente y el que está mejor representado en los niveles correspondientes a momentos anteriores al siglo VIII. En Santa María de Hito constituyen cerca del 80\% de las sepulturas de la fase antigua. Hay zonas en las que se disponen en dos niveles superpuestos (figura 4) y están ligadas a un modelo intensivo de gestión del espacio funerario en el que son frecuentes las destrucciones de sepulturas anteriores para emplazar otras nuevas. En ocasiones estas fosas aparecen delimitadas por bloques de piedra irregulares, conformando lo que se conoce como "tumba de murete". Estos acondicionamientos de las fosas con material pétreo no conforman en ningún caso cistas regulares.

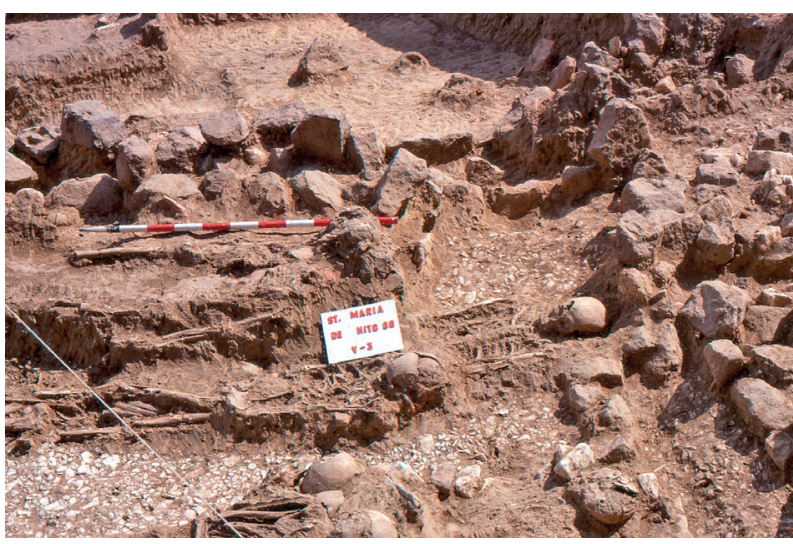

Fig. 4. Sepulturas de Santa María de Hito superpuestas sobre un suelo de la villa romana. Foto: R. Gimeno García-Lomas.

Menos habitual es el uso de ataúdes de madera, aunque también fueron utilizados. El principal indicio de su presencia son los herrajes metálicos: clavos y escarpias de hierro, o piezas tan características como las cantoneras, de tradición romana, habituales por ejemplo en la necrópolis Norte de La Olmeda (Abásolo et al., 1997). Aunque el volumen de estos elementos metálicos en algunos enclaves hace suponer que el empleo de ataúdes de madera era más frecuente, son pocos los casos identificados con precisión sobre el terreno. Los ejemplares documentados en Santa María de Hito y en El Conventón -donde se ha delimitado alguna sepultura con este tipo de contenedor en las actuaciones arqueológicas más recientes- permiten reconstruir las características generales de los ataúdes: cajones de forma rectangular o ligeramente trapezoidal, con anchura suficiente para no forzar la posición del cuerpo y en los que la tablazón se une mediante clavos de hierro. Existen indicios de que los ataúdes podrían haberse utilizado con mayor frecuencia en las primeras etapas de uso de las necrópolis. Para Santa María de Retortillo disponemos de una datación de ${ }^{14} \mathrm{C}$ obtenida de los restos óseos depositados en un ataúd de madera que permite fechar con cierta precisión el momento en el que se utilizó este tipo de contenedor, en torno a comienzos del siglo VI cal AD (GrN-26982: 1540 30 BP). En El Conventón un individuo adulto en un ataúd de madera forma parte de un conjunto junto con tres tumbas en fosa simple, una de ellas datada por ${ }^{14} \mathrm{C}$ en el siglo VI cal AD. En Santa María de Hito se constata que, al menos en algunas zonas, los ataúdes ocupan la base de la estratigrafía, infrapuestos a sepulturas en fosa simple. Además, la abundancia de herrajes me- 
tálicos desplazados de su posición primaria permite suponer que un cierto número proceda de sepulturas desmanteladas para colocar otras nuevas, ya en época visigoda.

Hay más dudas acerca del uso durante época visigoda de otros dos tipos de contenedores en las necrópolis del sur de Cantabria: las tumbas de lajas y los sarcófagos. El uso de tumbas construidas mediante lajas y bloques de piedra es común en el registro funerario de época visigoda en toda la península Ibérica, pero en Cantabria no contamos con ningún ejemplo seguro de cronología temprana. Sabemos que se empleaban losas de cubierta en algunas estructuras del siglo VII, como sucede en El Conventón de Rebolledo y no debemos descartar que algunas tumbas de lajas de Santa María de Hito y Santa María de Retortillo correspondan a la fase más antigua de uso del espacio funerario. En cualquier caso, no parece que se utilizasen con demasiada frecuencia antes del siglo VIII. En ocasiones, la superposición estratigráfica es evidente y recurrente, con las tumbas de lajas en los niveles superiores y de fosa imple, murete o ataúd en los inferiores. Las dataciones de radiocarbono disponibles contribuyen a fijar ese horizonte tardío, ya que los ejemplares con estimaciones más tempranas impiden asegurar el uso de tumbas de lajas antes de inicios del siglo VIII cal AD en Santa María de Hito (CSIC-837: 1320 $\pm 50 \mathrm{BP}$ ) e incluso en un momento más tardío, hacia la primera mitad del siglo IX cal AD en El Conventón de Rebolledo (GrN-15630: 1200 \pm 20 BP).

Por lo que respecta a los sarcófagos, hay indicios que invitan a pensar que se emplearon algunos modelos en momentos tempranos, especialmente los ejemplares de caliza blanca -llamada "toba" en algunos casos- decorados con motivos geométricos incisos. Este tipo de sarcófago, muy diferente tanto en materia prima como en aspectos formales - paredes de escaso grosor, cubiertas con encaje, ausencia de vanos antropomorfos- al que se utilizará a partir del siglo IX, está presente en todas las necrópolis

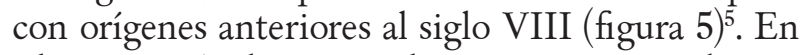
El Conventón los restos humanos recuperados en

5 Además de los ejemplares bien documentados de Santa María de Hito y de El Conventón, hay descripciones de sarcófagos de este tipo hallados por J. Carballo en Santa María de Retortillo: "de toba, completamente distinto a los demás (...) la superficie externa tiene dibujos grabados, sencillos, geométricos, cada línea de dos surcos con triple línea”, Diario de las excavaciones en Juliobriga (Reinosa) durante el año 1940, Archivo MUPAC, Carpeta Excavaciones II. un sarcófago de caliza blanca trapezoidal, con el hueco de la misma forma han sido datados por ${ }^{14} \mathrm{C}$ en torno a finales del siglo VIII cal AD (GrN-13776: $1230 \pm 40 \mathrm{BP})^{6}$. Este tipo de sarcófagos también están presentes en el $\mathrm{N}$ de Burgos y en lugares como Santa María de los Reyes Godos han sido fechados entre finales del siglo IV y el siglo V (Lecanda, 2015, 657), cronología quizá demasiado temprana. La similitud de la roca empleada y algunas características formales de los sarcófagos con ejemplares que aparecen en el $\mathrm{N}$ de Burgos, zona en la que se conocen incluso las canteras de extracción de los bloques que servirán para conformarlos, permite plantear la posibilidad de que algunos de ellos hayan llegado a Cantabria desde esa zona. Este transporte a media distancia reproduciría a pequeña escala los modelos de distribución de este tipo de elementos definidos para la Antigüedad Tardía (Ripoll, 1993), lo que constituiría otro argumento a favor de su atribución a época visigoda.

La presencia de ajuares en las sepulturas es, en términos generales, muy poco habitual. Este hecho puede tener que ver con la propia cronología de los conjuntos, ya que la mayor parte de las sepulturas se sitúan en el siglo VII, un momento en el que ha decaído de forma considerable el depósito de objetos, pero no parece explicación suficiente. La escasez de objetos es común a todos los lugares estudiados y también atañe a las sepulturas más antiguas, sobre todo en lo que se refiere a elementos tan característicos como las guarniciones de cinturón, sin que tampoco se pueda aducir que estemos ante productos ajenos al registro material de las poblaciones de la época en este territorio. En otro tipo de contextos, especialmente en las cuevas sepulcrales -sirva como ejemplo la colección procedente de Las Penas (Piélagos) (Serna et al., 2005) -están suficientemente representados como para considerar estos elementos como de uso habitual.

6 En la base de datos del laboratorio de la Universidad de Groningen esta muestra aparece identificada como $\mathrm{n}^{\mathrm{0}} 12$ del plano del edificio (García Guinea, 1985, fig. 6), que se corresponde con un sarcófago que, todavía en la actualidad, se conserva en su posición original en el yacimiento. Posteriormente, E. Van den Eynde atribuye esta datación a una tumba de lajas excavada en 1986 y situada junto a la iglesia (Sector 1.86, tumba BC). El Instituto Sautuola guarda un documento que confirma la primera atribución, y además sabemos que en 1986 se enviaron al laboratorio de Groningen dos muestras recogidas en las primeras excavaciones, anteriores a 1985, -una de las cuales sería la del sarcófagomientras que las dos siguientes corresponden a 1987. 

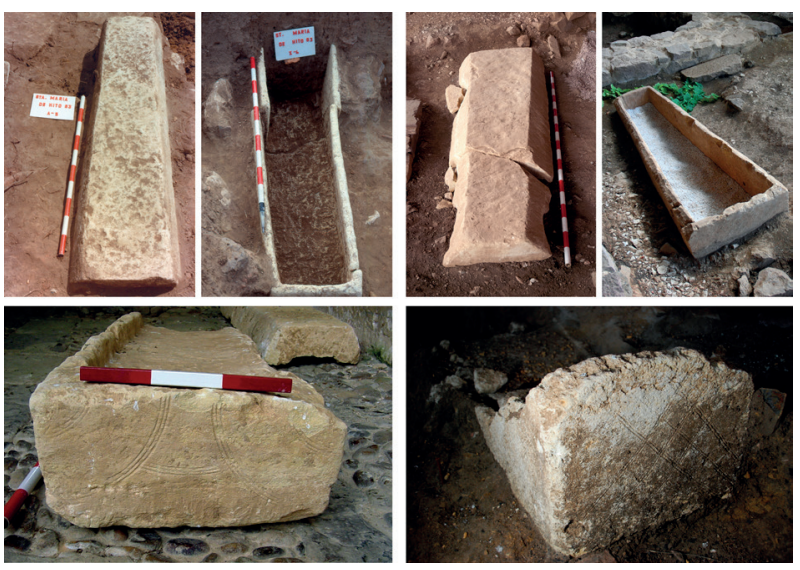

Fig. 5. Sarcófagos de Santa María de Hito (izq.) y El Conventón (dcha.). Fotos: R. Gimeno García Lomas y E. Gutiérrez Cuenca.

Tampoco son convincentes las interpretaciones que recurren al argumento de la "pobreza" entendida como falta de capacidad para acceder a determinados bienes o materiales, si tenemos en cuenta objetos como los anillos de oro y plata o el broche de hueso en Santa María de Hito, suficientemente ostentosos y lujosos. Parece que se conjugan dos factores: una pérdida de significado de las prácticas en las que los objetos de adorno personal tuvieron relevancia; y una tendencia a la inversión en bienes intangibles, especialmente a través de donaciones. Quizá también pueda tener relevancia el papel de las jerarquías eclesiásticas que, como señalan algunos investigadores (Larrea, 2016), pudieron dejar su impronta en el registro arqueológico a través de un lenguaje simbólico propio.

Enlazando con esta cuestión, merece atención especial un objeto singular: el broche de hueso de Santa María de Hito (figura 6), sobre el que se han hecho aportaciones relevantes. Aunque en el momento de su hallazgo se consideró una pieza mozárabe del siglo X (Gimeno, 1978), datación y atribución cultural mantenidas por algunos investigadores hasta fechas recientes (García Guinea, 2006), diversos investigadores (Martin, 1988; Werner, 1990; Gutiérrez Cuenca y Hierro Gárate, 2007) han permitido fijar su cronología en torno al siglo VII. No se conoce con qué sepultura estaba asociado -su hallazgo casual fue anterior al inicio de la excavación arqueológica- pero, como otros objetos que aparecen en esta misma fase del cementerio -especialmente los anillos de oro y plata- podría tener que ver con un individuo de elevada jerarquía civil o eclesiástica. Para broches de hueso de otras zo- nas de Europa, especialmente en áreas de influencia burgundia, se ha planteado el uso por parte de clérigos, aunque no de forma privativa (Martin, 1988). La decoración presente en el broche no es un mero ornamento, sino que responde a un programa iconográfico de carácter cristiano a partir del tema del Árbol de la Vida (Barroso y Morín, 1993) que se puede vincular con el arte visigodo del siglo VII. Es una representación trinitaria jerarquizada, de tradición anicónica, en la que el motivo vegetal central, de mayor tamaño, se identifica con Dios Padre, el de la izquierda con Espíritu Santo, que alimenta a sendas las palomas, mientras que el de la derecha representaría a Jesucristo, alimentando a pavos reales. Al margen de otras consideraciones, redunda en el carácter cristiano de las comunidades que utilizan esta necrópolis.

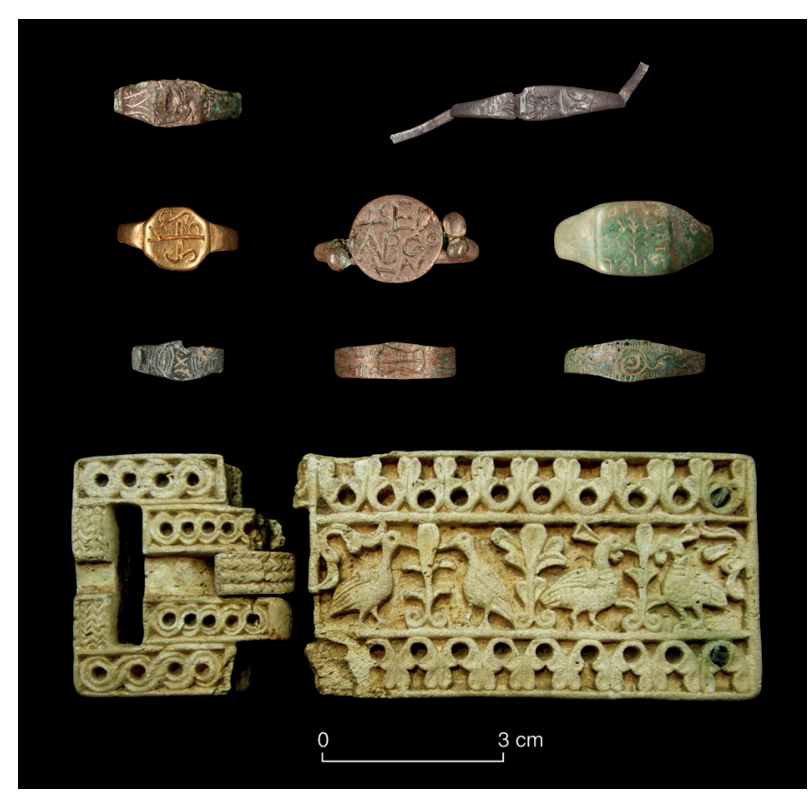

Fig. 6. Anillos y broche de hueso de Santa María de Hito. Fotos: E. Gutiérrez Cuenca (anillos) y MUPAC (broche).

Y si los elementos de atuendo y de adorno personal son poco habituales, mucho menos frecuente el depósito de otro tipo de objetos acompañando a las sepulturas. Se podrían interpretar como un depósito intencional dos cucharillas de bronce con cazoleta circular (figura 7) halladas dentro de una tumba de Santa María de Retortillo durante las excavaciones de J. Carballo. La tipología de ambas cucharillas o ligulae es indudablemente de época romana, con una cronología que podría remontarse incluso al siglo I d. de C. (Borobia, 1988), pero se especifica que aparecieron 
"dentro de una sepultura" 7 . La presencia de cucharillas en sepulturas de los siglos VI-VII no es del todo excepcional. El ejemplo más próximo lo tenemos en el hallazgo de sendas cucharillas de plata -decorada con una escena mitológica y con la inscripción ASRECI, interpretada como el nombre del propietario- y bronce en dos tumbas del siglo VI de la necrópolis de San Martín de Dulantzi (Álava), en ambos casos sujetadas por la mano del difunto (Loza Uriarte y Niso Lorenzo, 2011). En el caso alavés se trata, no obstante, de cucharas con cazoleta ovalada probablemente contemporáneas de las sepulturas, como sucede en otras necrópolis con hallazgos semejantes en la Galia Merovingia como Ichtratzheim (Alsacia) (Fischer et al., 2014). Para Retortillo la cronología antigua de las cucharas plantea algunas dudas sobre su relación con las sepulturas de época visigoda. No obstante, en las Islas Británicas encontramos ejemplos del uso con carácter simbólico de objetos de época romana temprana tanto en contextos funerarios anglosajones de los siglos V-VII (Eckardt y Williams, 2003), como en tumbas pleno y bajomedievales (Gilchrist, 2008).

Un último aspecto en relación con los ajuares que reviste cierto interés es la identificación de gestos que están presentes en otras necrópolis de

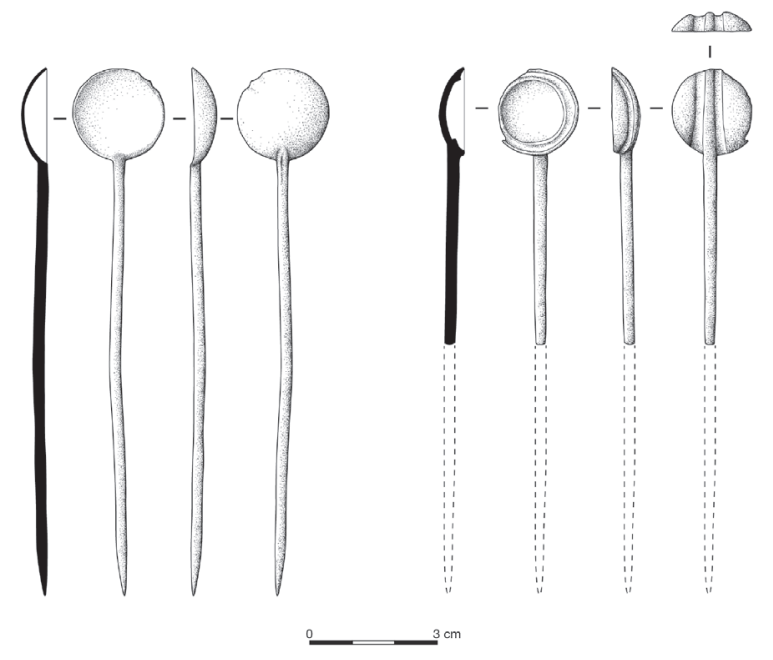

Fig. 7. Cucharillas romanas halladas por J. Carballo en el interior de una sepultura de la necrópolis de Santa María de Retortillo. Dibujo: E. Gutiérrez Cuenca.

7 Así lo hace constar J. Carballo, quien describe los objetos como "dos alfileres de bronce con cabeza de botón", Diario de las excavaciones en Juliobriga (Reinosa) durante el año 1940, Archivo MUPAC, Carpeta Excavaciones II. época visigoda. El hallazgo in situ de una cantidad significativa de anillos en Santa María de Hito ha permitido constatar algunas pautas identificadas en otros lugares. Sucede así con la reiterada aparición de anillos colocados en dedos de la mano izquierda $y$, al menos en los casos donde se ha podido comprobar, portados por individuos adultos de sexo femenino. Una tendencia similar se observa en $\mathrm{Ca}-$ cera de las Ranas (Madrid) (Ardanaz, 2000, 270). Otro dato relevante que se ha podido constatar es que, al menos en tres casos, aparecen dos anillos, por lo general uno de aleación de cobre y otro de plata, colocados en el mismo dedo. Parece que se trata de una práctica habitual en época visigoda, que hemos identificado en diversas necrópolis como la de Duratón (Segovia) (Molinero, 1948), Cacera de las Ranas (Madrid) (Ardanaz, 2000) o Casa Herrera (Badajoz) (Caballero y Ulbert, 1976) y también en la de Herrera de Pisuerga (Palencia) (Martínez Santa-Olalla, 1933). Esta última identificación es especialmente significativa desde el punto de vista historiográfico porque era el lugar al que se hacía de forma implícita - por su proximidad geográfica- cuando se tildaba de "ajenas" a Cantabria a las manifestaciones culturales y simbólicas hispanovisigodas (García Guinea y Van den Eynde, 1991).

\section{CAMBIOS EN TORNO AL SIGLO VIII}

En torno al siglo VIII se van a producir cambios apreciables que afectan a los espacios funerarios, el más relevante de los cuales va a tener que ver con la introducción de la inhumación ad sanctos y apud ecclesiam en el medio rural. Se establecerá a partir de este momento, aunque será más visible a partir del siglo IX, un vínculo indisoluble entre edificios religiosos y cementerios que se mantendrá vigente, en diferentes formatos, por espacio de al menos diez siglos.

En las necrópolis que analizamos en este trabajo los edificios de culto se van a establecer sobre espacios funerarios ya en uso, aunque no podemos establecer con precisión en todos los casos cuál fue el momento concreto en el que se produjo la transformación que permitirá que haya una continuidad en el tránsito hacia la Edad Media. Conviene señalar que en ninguno de los ejemplos del sur de Cantabria ha sido posible identificar la relación entre sepulturas anteriores al siglo VIII y un edificio cristiano contemporáneo. Como sucede en el resto de la región, esta vinculación se produce en algún momento a lo largo de la Edad Media, -que- 
dando testimonio ya sea en forma de iglesia en pie o de iglesia en ruinas, o incluso en la toponimiaaunque la falta de documentación sobre el origen de la mayor parte de las iglesias altomedievales dificulta en gran medida analizar los tiempos de este proceso, con lo que nos manejamos en el terreno de las hipótesis.

Solo en el caso de El Conventón de Rebolledo tenemos indicios más o menos sólidos de que la construcción de la iglesia en torno a la que se organizaría el cementerio medieval que se superpone al uso funerario de época visigoda se produjo en torno al siglo VIII.

Las excavaciones realizadas entre 1983 y 1985 se extendieron hacia el $\mathrm{N}$ del edificio romano $\mathrm{y}$ dejaron a la vista los cimientos de una iglesia prerrománica (Van den Eynde, 2002). Este edificio estaba a una cota superior a la de las estructuras romanas y se asentaba sobre ellas, aunque no las aprovechaba para la cimentación ni seguía el mismo eje de orientación, sino que se orientaba hacia el E. Es el templo en torno al que se articula el cementerio a partir de época altomedieval, con sepulturas fechadas con seguridad desde la primera mitad del siglo IX.

La iglesia, que ocupa una posición central con respecto a la disposición de las sepulturas medievales en toda la extensión del yacimiento, tiene una nave de planta rectangular y cabecera también de planta rectangular (figura 8). Su carácter prerrománico y el origen de la fábrica en torno a los siglos VIII-IX ha sido establecido fundamentalmente a partir de tres argumentos: no presenta ningún elemento románico, estilo arquitectónico que a partir del siglo XII se impone en la comarca; han aparecido fragmentos de uno o dos capiteles de tipo corintio, con una cronología de los siglos VI-IX (Pérez, 1985; Van den Eynde, 2002) y una "seria impronta visigoda"; y la modulación de sus dimensiones (Bohigas et al., 2005) es coincidente con la de otras iglesias construidas en época visigoda y altomedieval. Los datos cronológicos que aporta la excavación de la necrópolis asociada al templo abundan en este carácter prerrománico y permitirían fechar su construcción en el siglo VIII. En el interior de la nave aparecieron dos sarcófagos de caliza blanca de planta y vano trapezoidal, uno con la cubierta de sección trapezoidal decorada con círculos concéntricos y otro con la cubierta de sección semicircular y siete tumbas de lajas de individuos infantiles de corta edad. Los
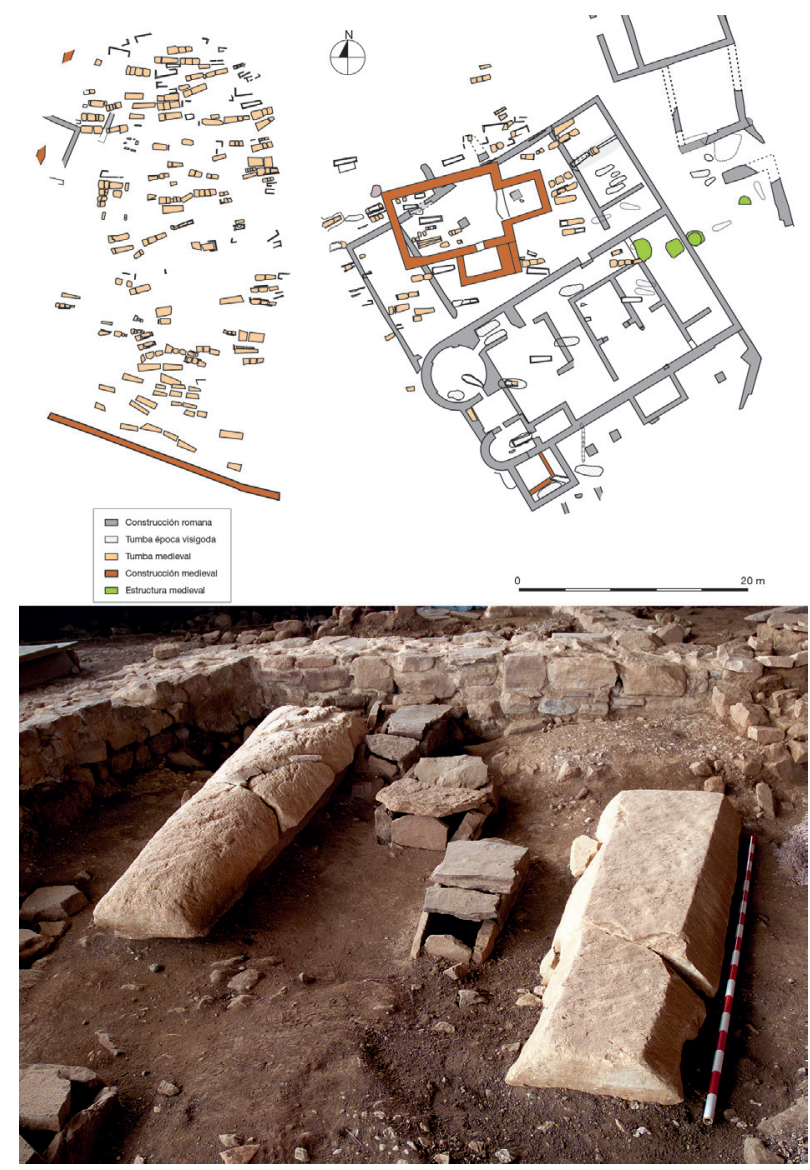

Fig. 8. Iglesia de El Conventón. Plano: Fernández et alii, 2016. Foto: E. Gutiérrez Cuenca.

sarcófagos guardan gran similitud con ejemplares hallados en Santa María de Hito, una tipología sobre cuya cronología temprana ya hemos tratado en este trabajo.

Los sarcófagos aparecen bajo un pavimento empedrado que podría corresponderse a una reforma en un momento avanzado del uso del edificio -no hay que olvidar que los sarcófagos altomedievales, incluso con decoraciones exteriores en la caja y en la tapa, se solían enterrar en una fosa y no quedaban exentos- que los ocultó a la vista bajo el suelo de la nave.

Aunque este conjunto de tumbas ubicadas en el interior de la iglesia se ha querido identificar como una agrupación familiar, el alto número de tumbas infantiles no parece encajar en una interpretación de este tipo. Quizá originariamente fuese una agrupación familiar - los individuos adultos de los sarcófagos se podrían identificar, a modo de hipótesis, con los fundadores de la iglesia, aunque solo sabemos el sexo, varón, del que ocupaba el sarcófago de 
cubierta decorada-, pero después este espacio interior quedaría reservado a individuos únicamente infantiles, sin que se pueda determinar que todos pertenezcan al mismo grupo familiar. De hecho, no es la única zona de la necrópolis en la que las tumbas infantiles se agrupan formando un conjunto de cierta densidad y al W de la iglesia aparecen otras concentraciones de este tipo. En relación con la distribución de los sarcófagos, conviene señalar que únicamente están presentes en el interior de la iglesia y en su entorno inmediato, y en la zona situada al S-SE de la misma, mientras que no se ha identificado ningún ejemplar en las zonas más lejanas a los muros hacia las que se expande la necrópolis altomedieval de tumbas de lajas.

Sobre la cronología de esas tumbas que quedan dentro de los muros del edificio religioso existen dos posibilidades: que los sarcófagos pertenezcan al momento inicial de la iglesia y sean de sus fundadores, constituyendo un ejemplo de uso privilegiado del interior del templo, presente todavía en algunas iglesias de época visigoda (Martínez Tejera, 1993); o que sean anteriores a la construcción y se haya producido una superposición casual. Como argumento a favor del carácter privilegiado de las sepulturas principales está el hecho de que ocupan un lugar opuesto al ábside, de un modo similar a los contraábsides con función funeraria (Bango Torviso, 1992). Además es significativa la circunstancia de que se trate de dos sarcófagos, el tipo de contenedor reservado para los personajes más relevantes de la época y que, al margen de las sepulturas infantiles, que también ocupan un lugar alejado del ábside, son las únicas estructuras funerarias que se documentan, y no hay ninguna tumba en el resto del edificio, ni bajo sus muros. Nos encontraríamos ante un modelo de capilla funeraria con paralelos en la Francia merovingia, como La Chapelle de Jau-Dignac-etLoirac, un ejemplo de necrópolis de tipo familiar con las sepulturas más antiguas en el interior del edificio de culto, concebido con ese fin, y el resto alrededor de sus "ancestros" (Cartron y Castex, 2015) cuya fundación se sitúa en el siglo VII y tiene continuidad de uso hasta el siglo XI. Encaja con la actividad constructiva con fines funerarios desarrollada por la élites locales al final de la época visigoda (Chavarría, 2010).

Algunas de las tumbas infantiles pueden estar relacionadas con los sarcófagos, sobre todo las más próximas, y responder a vínculos familiares, pero la presencia de tantos ejemplares de edades muy próximas parece responder a un modelo de uso particular en el que se permite, de forma excepcional, el enterramiento de niños en el interior del templo.

Quedan, no obstante, algunas cuestiones por resolver para validar esta hipótesis sobre la cronología temprana y la función de capilla funeraria del edificio de El Conventón. A diferencia de la compartimentación de la necrópolis, que utiliza, aparentemente, espacios del edificio romano visibles y en pie, la iglesia se dispone con una orientación diferente e ignorando las estructuras subyacentes a las que se superpone. Por lo que se refiere a la tipología constructiva, corresponde con un modelo sencillo que no permite una datación precisa. Situarnos en el siglo VIII nos enfrenta, además, a un momento de turbulencias económicas, sociales y políticas aunque es probable que no afectasen de forma inmediata a los sistemas locales de la zona más septentrional del periclitado reino visigodo.

Otro cambio significativo que se produce en torno al siglo VIII y que se constata en las necrópolis del sur de Cantabria es la desaparición de los ajuares en las tumbas. Veremos a continuación cómo la generalización de la sepultura ad sanctos en el medio rural y la desaparición de los ajuares pueden ser tendencias de un mismo proceso, relacionadas con un cambio de paradigma que se estaba produciendo desde el siglo VII y en el que los cambios sociopolíticos quizá sirvieron como catalizador.

Como ya hemos señalado, la presencia de objetos acompañando a los difuntos -tanto los relacionados con la indumentaria como los depósitos propiamente dichos- no es demasiado frecuente entre otras cosas porque el registro de la región corresponde a una época en la que esta costumbre estaba cayendo en desuso, coincidiendo con otras transformaciones que se observan en los espacios cementeriales. No podemos hacer una aproximación estadística fiable por los defectos que presenta la documentación, incluso en los casos mejor conocidos. No obstante, ni siquiera en Santa María de Hito, donde es más frecuente la presencia de objetos relacionados con la indumentaria o el adorno personal en las sepulturas, la proporción superaría el 10\%. Tampoco podemos saber si se producen cambios a lo largo de los diferentes momentos de uso de esta necrópolis, más allá de la constatación efectiva de que en torno al siglo VIII los ajuares desaparecen y el espacio funerario sigue en uso, como sucede también en El Conventón. La mayor parte del registro corresponde a un momento en el que la inhumación vestida y 
los ajuares podrían haber perdido parte de su significado en el seno de las comunidades rurales. Puede que sigan siendo un marcador social o funcional de cierta trascendencia para algunos individuos, pero su escasa representación debe entenderse más como una excepción que como una pauta que ayude a comprender la organización de unas comunidades sobre las que, al menos en Cantabria, conocemos poco más que sus cementerios. Lo que sí parece claro es que el cambio de costumbre tiene más que ver con una pérdida de significado relacionada con transformaciones en las formas de ostentación o de representación de la posición económica y social ya sea en los términos en las que los entienden algunos investigadores (Quirós y Vigil-Escalera, 2011; Tejerizo, 2011) o ligada a cuestiones vinculadas a cambios en las creencias sobre la salvación del individuo, como veremos más adelante- que con prohibiciones o imposiciones motivadas por cuestiones religiosas como las que apunta J. López Quiroga (2010, 269), para quien el progresivo abandono de la costumbre de la inhumación vestida y del depósito de ajuares que se detecta a partir de finales del siglo VI y, sobre todo, durante el siglo VII, estaría ligado la influencia del cristianismo y la adopción del catolicismo como religión oficial del reino de Toledo, una fe que "rechaza frontalmente la presencia de cualquier elemento de adorno, depósito y/o ajuar en las inhumaciones”, y con la aculturación que la "minoría goda" recibe de la "élite hispano romana". Sin embargo, no contamos con ningún testimonio que respalde esta postura, y no hay disposiciones normativas que prohíban la costumbre. De hecho, la indumentaria juega un papel relevante en el rito funerario cristiano, tal y como se deduce de las indicaciones recogidas en el Liber Ordinum sobre las vestimentas que deben lucir los finados religiosos durante los funerales (Pinar y Turell, 2007).

Conviene señalar que, en el caso concreto de las guarniciones, sabemos que desaparecen de las sepulturas, pero siguen formando parte de la indumentaria, como señalaría su presencia en contextos de hábitat durante el siglo VIII, tal y como se constata en El Bovalar (Lérida) (Palol, 1986) o Gózquez (Madrid) (Vigil-Escalera, 2009), entre otros. También la presencia en cuevas sepulcrales cuyas cronologías alcanzan el primer tercio del siglo VIII (Gutiérrez y Hierro, 2015) apunta en este sentido.

La desaparición de los ajuares de las tumbas a partir del siglo VIII es una tendencia general en todo el occidente europeo, que se desarrolla de for- ma paralela al abandono de las necrópolis ubicadas fuera de los núcleos de población, todo ello en un momento de consolidación del cristianismo, que podría expresar un cambio general de actitud hacia la muerte y hacia los muertos (Meier y Graham Campbell, 2007, 440.

Ya E. Salin (1959, 234-235) desliga la presencia de objetos en las tumbas merovingias de cuestiones rituales o religiosas relacionadas con creencias precristianas, señalando la ausencia de disposiciones normativas o condenas explícitas como una señal de la falta de oposición por parte de las jerarquías eclesiásticas a este tipo de prácticas que irían desapareciendo al vaciarse del contenido simbólico relacionado con el prestigio social que tenían en origen. También C. Treffort (1996, 72-74) incide en la idea de que la inhumación vestida no debe considerarse una pervivencia pagana y llama la atención sobre el hecho de que el atuendo del difunto nunca ha sido objeto de regulación por parte de la iglesia en época merovingia y únicamente se conocen algunas disposiciones sobre la riqueza de los ornamentos para evitar la ostentación. Esta investigadora considera que la desaparición de los depósitos suntuarios de las tumbas que se produce a partir del siglo VII se puede explicar por la popularización de las actitudes de humildad promovidas por algunos religiosos y que comienzan manifestándose en las clases privilegiadas. En la misma línea se expresan otros autores (Pinar y Turell, 2007), relacionando las posiciones contrarias a la presencia de ornamentos en las sepulturas con el ideal de pobreza difundido por algunos padres de la Iglesia, al tiempo que recogen un testimonio del siglo VI en el que Teodorico I -significativamente, una autoridad civil y no religiosa- muestra cierta oposición al entierro con objetos de valor, más útiles para los vivos, y propone sustituir estos elementos por otros signos de ostentación, concretamente la construcción de edificios funerarios. Aquí es donde las dos tendencias más significativas que se aprecian a partir del siglo VIII confluyen.

Si todavía a finales del siglo VII o comienzos del siglo VIII el acompañar a los difuntos con ajuares es una práctica reconocible ${ }^{8}$, aunque minoritaria, a través de la que se manifiesta el prestigio social, todo apunta a que está siendo sustituida por otras mo-

8 En opinión de algunos investigadores, en esta última etapa de uso los ajuares podrían haber experimentado incluso cambios en su significado, convirtiéndose en elementos transmisores de la memoria de los linajes ligados a individuos femeninos (Williams, 2010). 
dalidades de amortización del patrimonio como las donaciones pro anima (Treffort, 1996, 183-184), que van a tener especial impacto en la configuración del primer "mapa eclesiástico", sobre todo en el ámbito rural. La proliferación de donaciones y fundaciones en favor de la Iglesia que se recogen como últimas voluntades en la documentación altomedieval disponible para los siglos IX y siguientes -en el caso de Cantabria no disponemos de testimonios escritos anteriores- puede ser considerada un reflejo de la cristalización de este cambio de tendencia en la "inversión en el más allá" en la que se busca garantizar la salvación individual. Ya desde época visigoda parece que la aristocracia se implica en la construcción de edificios religiosos, en algunos de los cuales la función funeraria es un elemento relevante (Chavarría, 2010). Comparte una interpretación semejante I. Martín Viso (2014, 117-118), quien considera que puede tratarse de un cambio en el comportamiento de las aristocracias mediante el cual la creación y dotación de monasterios propios o las donaciones post mortem sustituyen antiguas fórmulas de representación. Un proceso similar se observa en algunas regiones de Francia, donde la construcción de edificios religiosos y capillas funerarias toma el relevo de los ajuares como manifestación de diferenciación social (Halsall, 1995, 262-282) a partir del siglo VII. También en Italia la conservación de la memoria de la aristocracia se canaliza a partir de los siglos VIII-IX a través de donaciones pro anima que implican sepulturas preferentes en las iglesias o monasterios que las reciben (La Rocca, 1998).

Los cambios que se aprecian a partir del siglo VIII permiten suponer una relación estrecha entre la desaparición de las sepulturas con ajuar y la proliferación de nuevos cementerios en las inmediaciones de todo tipo de edificios religiosos durante los primeros siglos de la Edad Media. La inversión o la amortización de objetos suntuarios en los funerales se sustituyen, en el caso de los individuos con más rentas, por la dotación o construcción de templos en los que enterrarse, un acto que -de forma voluntaria o involuntaria- tendrá consecuencias en la forma de enterrarse de toda la comunidad. Como señala C. Treffort (1996), las donaciones pro anima sustituyen al depósito de ajuares en las tumbas y así lo dejan ver los documentos escritos, donde se recogen innumerables donaciones de fincas, de rentas, de templos, de ajuares para oficios religiosos o incluso de dinero en efectivo para propiciar la salvación. La búsqueda de la propia salvación a través de la inversión de los bienes materiales que realizan los más pudientes, que se traduce en una proliferación de edificios de culto en los que perpetuar su memoria (La Rocca, 1998), facilitaría el "acceso a la salvación" - mediante el enterramiento ad sanctos- a quienes hasta ese momento recibían sepultura en cementerios sin templo, ya que estos edificios religiosos funcionarán como un polo de atracción de nuevas sepulturas o como elemento de consolidación y vía de continuidad para espacios funerarios en uso. El principal elemento de ostentación o de posicionamiento social en el momento de la muerte pasará a ser, a partir de ese momento, la ubicación de la sepultura en un emplazamiento a los elementos que puedan interceder por la salvación del difunto: las reliquias, el altar, etc. o los propios fundadores de las capillas, vistos por la comunidad como personas virtuosas.

A pesar de las disposiciones restrictivas vigentes desde el primer concilio de Braga (561) sobre las sepulturas en el interior de las iglesias en el Regnum Visigothorum, es posible que muchos pequeños templos construidos en el ámbito rural por las élites locales quedasen al margen del control de la autoridad episcopal o su dotación resultase lo suficientemente interesante para la institución eclesiástica como para permitir un uso funerario restringido. No conviene olvidar que esta interdicción no estaba vigente en otros territorios cristianos $y$, por ejemplo, la iglesia merovingia permitía en el concilio de Mainz (813) la sepultura en el interior del tempo a legos de señalada virtud, categoría que incluiría a los más generosos donantes.

\section{LA CONTINUIDAD COMO NORMA: DE LA}

NECRÓPOLIS VISIGODA AL CEMENTERIO MEDIEVAL

El papel evidente de las necrópolis de época visigoda en la génesis del cementerio cristiano específicamente medieval, con las características que lo definen en términos generales hasta el siglo XV, lo encontramos en la continuidad como pauta más destacable. Continuidad en el espacio utilizado y en las formas funerarias empleadas. De hecho, cuanto más difícil es establecer el momento preciso del cambio, más peso tienen los argumentos en favor del continuismo. Es cierto que se observan diferencias lo suficientemente significativas, desde nuestro punto de vista, como para establecer una división entre un cementerio de época visigoda y otro específicamente medieval, pero los procesos de cambio tienen más que ver con una mutación y un progresivo cambio de costumbres que con la aparente ruptura que se refleja en el registro ar- 
queológico, sobre todo a partir del siglo VIII, pero que seguramente llevaba un tiempo produciéndose.

La nueva configuración de espacios funerarios ad sanctos y apud ecclesiam será clave en la consolidación y el desarrollo de un primer modelo de cementerio medieval que se desarrollará con unas características comunes hasta al menos el umbral del siglo XIII: contenedores más voluminosos como tumbas de lajas o sarcófagos, recintos de gran extensión sin superposiciones, uso de elementos de señalización, ausencia de ajuares, etc.

La transformación más evidente se aprecia en un cambio en la tipología constructiva: a partir del siglo VIII se generaliza el uso de tumbas de lajas, ahora sí con dataciones de ${ }^{14} \mathrm{C}$, en estrecha relación con un nuevo modelo de gestión del espacio funerario que hemos definido como cementerio altomedieval extensivo (Gutiérrez Cuenca, 2015, 472-474).

$\mathrm{Si}$ atendemos a los datos que proporciona la cronología radiocarbónica, el arco cronológico de uso de este tipo de estructuras como contenedor sepulcral comprende un amplio periodo de tiempo de más de 600 años, algo más largo de lo que se considera habitualmente, con los extremos señalados por las fechas de una tumba de Santa María de Hito ya mencionada, en torno a inicios del siglo VIII (CSIC-837: $1320 \pm 50$ BP), y otra de Santa María de Bareyo en torno a inicios del siglo XIV (UGRA-611: 690 \pm 60 $\mathrm{BP}$ ), aunque en este último caso se trata de un contenedor reutilizado y la datación podría estar señalando el uso más reciente de una estructura construida con anterioridad. La mayor parte de las fechas, si tenemos en cuenta el valor medio de la datación, se concentran entre los siglos IX y XII lo que supone más del 80\% de las referencias disponibles y confirma esa etapa altomedieval como el periodo en el que se utilizan las tumbas de lajas con mayor profusión.

Por lo que respecta a las cuestiones ligadas con la noción de continuidad, es interesante constatar que en algunos cementerios se observan comportamientos en los que los nexos con el periodo anterior que van más allá de la mera reiteración en la localización. El empleo más interesante en las necrópolis meridionales es el reaprovechamiento sistemático de fragmentos de sarcófago documentado en Santa María de Hito.

En esa necrópolis se utilizan como material para la construcción de las tumbas de lajas fragmentos de sarcófagos de caliza blanca y, en menor medida, ladrillos del hypocaustum de la villa romana sobre la que se asienta el cementerio (figura 9). En ambos casos son materiales de disponibilidad inmediata, procedentes de las estructuras romanas y de las fases más antiguas de la necrópolis. Sin embargo, mientras que los ladrillos romanos aparecen de un forma casi testimonial y con evidente sesgo funcional -se emplean como orejeras o en el cierre de los lados cortos de las cistas, sin necesidad de transformación- el uso de fragmentos de sarcófago es mucho más habitual, ya que están presentes en cerca del $40 \%$ de las tumbas, y la forma de emplearlos menos concreta: en ocasiones son grandes fragmentos, en otros pequeñas piezas, se emplean en la cubierta, en los laterales o como orejeras, con una profusión que hace sospechar que el uso trasciende el aprovechamiento fortuito y esconde algún significado simbólico. Quizá se trate de una práctica que manifiesta una voluntad de vincularse con los ancestros, representados por sepulturas anteriores con respecto de las que se ha perdido la memoria, integrada en las propias creencias cristianas. En su momento ya nos inclinamos por la posibilidad de que sea una variante particular de crecimiento de una necrópolis en torno a una o varias tumbas fundacionales, un fenómeno detectado en el ámbito merovingio (Martín Viso, 2014, 101). Creemos, incluso, que podría entenderse como una interpretación un tanto peculiar de le sepultura ad sanctos, en la misma línea en la que se producen ocupaciones de mausoleos o se establecen pequeñas necrópolis en torno a sarcófagos de personajes notables durante la Antigüedad Tardía sin que exista una figura martirial o una santidad evidente, aunque en este caso se trate de un momento algo más tardío.

Consolidado el uso funerario en Santa María de Hito, Santa María de Retortillo y El Conventón de Rebolledo más allá del siglo VIII, una visión diacrónica extensa permite apreciar que nos encontramos con dos modelos diferentes en su proyección hacia los siglos medievales.

En los dos primeros casos la función cementerial del entorno de la iglesia se va a perpetuar durante toda la Eda Media -con los cambios de organización que se producen a lo largo del periodo: expansión altomedieval, contracción bajomedieval, cambios de tipologías funerarias, etc.- hasta el siguiente cambio profundo, que será el desplazamiento de las sepulturas al interior del edificio de culto a inicios de la Edad Moderna, e incluso perdurará hasta el siglo XX, con pequeños cementerios colindantes a la iglesia. En Santa María de Hito es donde mejor encontramos representado todo el proceso. El cementerio llegó a su máxima extensión en torno al siglo XII, momento en el que ocupaba más 
de $1000 \mathrm{~m}^{2}$ de superficie. Será entonces cuando las zonas más lejanas de la iglesia, sobre todo el sector NW dejen de utilizarse con fines funerarios, como lo estaría indicando la presencia de un nivel con importantes acumulaciones de material cerámico fechado entre finales del siglo XI y principios del XII (Gimeno, 1986). A partir del siglo XIII la superficie del cementerio quedará sensiblemente reducida y solo se utilizarán las zonas más próximas a la iglesia. Las sepulturas se concentran en la zona $S$, próximas al acceso al templo, donde se identificó una secuencia de amplio desarrollo vertical ausente en otras zonas más distantes de los muros de la iglesia. Las tipologías funerarias indican que el cementerio exterior sigue en uso durante toda la Baja Edad Media.

El Conventón, sin embargo, va a estar en uso como cementerio medieval durante un lapso mucho menor. No hay evidencias arqueológicas que permitan sostener una prolongación más allá del siglo XII y lo más
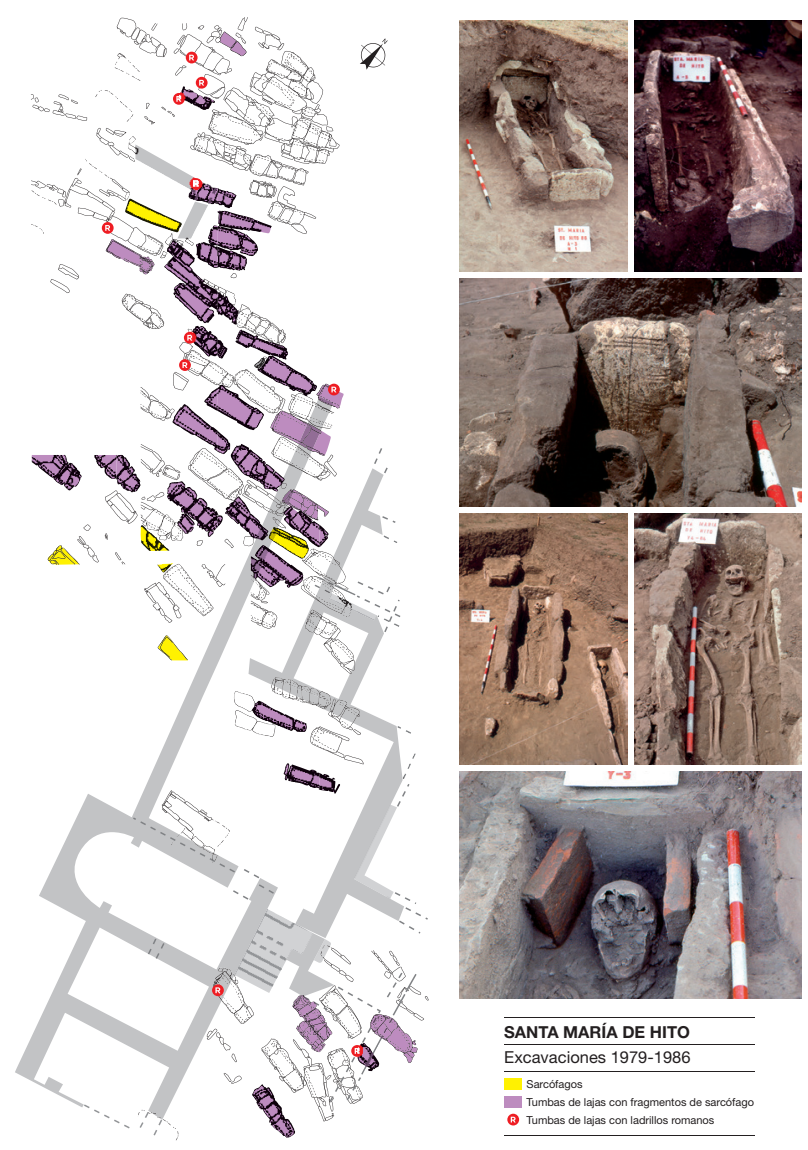

Fig. 9. Tumbas de lajas con reutilización de fragmentos de sarcófago y ladrillos romanos en Santa María de Hito. Plano: R. Gimeno García-Lomas (modificado). Fotos: R. Gimeno García-Lomas. probable es que el abandono fuese simultáneo y afectase tanto al cementerio como a la iglesia en torno a la cual se disponía. El testigo de ambas funciones, funeraria y litúrgica, lo recogerán las iglesias aún hoy en uso de las aldeas próximas, Rebolledo y Camesa. Todo apunta a que El Conventón fue una de las víctimas del proceso de consolidación de la parroquia territorial que culmina en torno al siglo XIII. Conforme al modelo propuesto más arriba, quizá su origen como iglesia propia, dotada como una capilla funeraria por sus fundadores en un momento temprano, tuvo algo que ver con que no se convirtiese en parroquia. Es una hipótesis, no obstante, que la ausencia de documentación escrita no permite contrastar.

\section{CONCLUSIONES}

El tránsito hacia la Edad Media en el sur de Cantabria muestra una ruptura evidente con el mundo romano en lo que respecta al uso de las antiguas estructuras habitacionales. Se produce una transformación en espacios funerarios de antiguos espacios de hábitat, en ocasiones abandonados durante largo tiempo. En algunos casos está claro que hay un aprovechamiento intencionado de estructuras, aunque con los datos disponibles no se puede dar una explicación global a la reocupación de edificios romanos con nuevos usos que poco tienen que ver con su trayectoria previa.

Hemos insistido en la necesidad de superar la visión sesgada que ofrecía la historiografía tradicional, que presentaba una lectura distorsionada del registro arqueológico de los siglos VI-VIII que no queda respaldada tras su revisión. No hay argumentos sólidos que permitan sostener una excepcional situación social o religiosa para Cantabria, sino que el territorio que se comporta en muchos aspectos de manera similar a otros del Regnum Visigothorum. Esto se hace extensible a las prácticas funerarias, en las que se aprecia la variabilidad propia del momento, pero que no reflejan en modo alguno el pretendido particularismo defendido por las interpretaciones históricas más conservadoras.

Aunque se aprecian diferencias entre la etapa de época visigoda y la específicamente medieval posterior al siglo VIII, tanto en tipologías funerarias, como en modelos de gestión o en los objetos que acompañan a los difuntos, es tanto o más relevante la continuidad que se produce en el uso de los espacios funerarios cristianos. Este fenómeno se consolida durante la Alta Edad Media y alcanza, en el peor de los casos, el siglo XII, manifestándose en 
ocasiones como un recorrido ininterrumpido por todas las fórmulas de organización cementerial en el en el entorno de los templos cristianos desde su origen hasta la actualidad.

Algunas transformaciones que se aprecian en el registro arqueológico son consecuencia de procesos complejos en las formas de representación social y en el ámbito de las creencias que aparentemente están en el siglo VIII en pleno proceso de cambio. Es interesante destacar cómo las actitudes individuales contribuyen a transformar los comportamientos colectivos y, de forma evidente, el paisaje. Nos referimos especialmente a la multiplicación de edificios de culto y de espacios funerarios que se produce en la Alta Edad Media, fenómeno muy evidente el impacto en el ámbito rural y que tendrá en el sur de Cantabria uno de sus escenarios.

\section{Bibliografía}

Abascal Palazón, J.M., Cebrián Fernández, R. y Sala-Sellés, F. (2008), "El vicus romano de 'Baños de la Reina' (Calpe, Alicante)”, Calp Història, 2,10-17.

Abásolo, J. A., Cortés, J. y Pérez Rodríguez-Aragón, F. (1997), La necrópolis norte de la Olmeda (Pedrosa de la Vega, Palencia), Diputación de Palencia, Palencia.

Alapont Martín, L. (2009), "El mundo funerario en el limes visigodo-bizantino: el territorio valenciano", Gausac, 34-35, 145-158.

Ardanaz Arranz, F. (2000), La necrópolis visigoda de Cacera de las Ranas (Aranjuez, Madrid), Madrid.

Arias Cabal, P., Ontañón Peredo, R., Gutiérrez Cuenca, E., Hierro Gárate, J.A., Etxeberria Gabilondo, F., Herrasti Erlogorri, L. y Uzquiano Ollero, P. (2017), "Hidden in the depths, far from the people. The funerary context in the Lower Gallery at La Garma and the use of natural caves as burial places in early medieval Cantabria (Northern Spain)", Cave Rituals in $\mathrm{Me}$ dieval Europe, $A D$ 500-1500 (K.A. Bergsvik y M. Dowd, Eds.), Oxford, 133-151.

Azkarate Garai-Olaun, A. (2002), "De la tardoantigüedad al medievo cristiano. Una mirada a los estudios arqueológicos sobre el mundo funerario", Espacios y usos funerarios en el Occidente Romano (D. Vaquerizo, Ed.), Córdoba, 115-140.

Bango Torviso, I. (1992), "El espacio para enterramientos privilegiados en la arquitectura medie- val española”, Anuario del Departamento de Historia y Teoría del Arte, IV, 93-132.

Barbero, A. y Vigil, M. (1974), Sobre los orígenes sociales de la Reconquista, Barcelona.

Barroso Cabrera, R. y Morín de Pablos, J. (1993), El Árbol de la Vida. Un estudio de iconografía visigoda: San Pedro de la Nave y Quintanilla de las Viñas, Madrid.

Besga Marroquín, A. (1983), Consideraciones sobre la situación política de los pueblos del norte de España durante la época visigoda del reino de Toledo, Bilbao.

Bienes Calvo, J.J. (2007), "El Mausoleo romano de La Torrecilla (Corella)”, La tierra te sea leve. Arqueología de la muerte en Navarra, Pamplona, 161-164.

Bohigas Roldán, R., Campuzano Ruiz, E. y Marcos Martínez, J. (2005), "Cueva Santa (Santo Toribio de Liébana, Camaleño, Cantabria): un monumento prerrománico en Cantabria”, Boletín de Arqueología Medieval, 12, 81-97.

Borobia Melendo, E.L. (1988), Instrumental médico-quirúrgico en la Hispania romana, Madrid.

Caballero Zoreda, L. y Ulbert, T. (1976), La basílica paleocristiana de Casa Herrera en las cercanías de Mérida (Badajoz), Madrid.

Carballo, J. (1941), "Descubrimiento de una ciudad romana”, Metalurgia y Electricidad, 43, 1822.

Carballo, J. (1909), "Una necrópolis en las minas de Solía (Santander)”, Boletín de La Real Sociedad Española de Historia Natural, IX, 324329.

Carballo, J. (1910), "Más datos acerca de la necrópolis de Solía", Boletín de La Real Sociedad Española de Historia Natural, X, 271-275.

Carballo, J. (1935), "La caverna de Suano (Reinosa)", Altamira, II.3, 233-252.

Cartron, I. y Castex, D. (2015), "Adaptation et transformation d'un cimetière du haut Moyen Âge en milieu estuarien: le site de Jau-Dignac et Loirac en Gironde", Rencontre autour des paysages du cimetière médiéval et moderne (M. Gaultier, A. Dietrich y A.Corrochano, Eds.), Tours, 81-87.

Chavarría Arnau, A. (2010), "Churches and aristocracies in seventh-century Spain: some thoughts on the debate on Visigothic churches", Early Medieval Europe, 18, 160-174.

Chavarría Arnau, A. (2007), El final de las villae 
en Hispania (siglos IV-VII D.C.), Turnhout.

Eckardt, H. y Williams, H. (2003), "Objects without a past? The use of Roman objects in early Anglo-Saxon graves", Archaeologies of Remembrance: Death and Memory in Past Societies (H. Williams, Ed.), Nueva York-Londres, 141-170.

Fernández Ochoa, C. y Gil Sendino, F. (2007), "La villa romana del 'Torrexón' de Veranes (Gijón). Nuevos datos sobre la transición al medievo en Asturias desde una perspectiva arqueológica”, Excavaciones arqueológicas en Asturias 1999-2002, Oviedo, 149-162.

Fernández Vega, P.A., Mantecón Callejo, L., Gómez, J.C., y Peñil Mínguez, J. (2016), "Excavaciones arqueológicas en Camesa-Rebolledo", Actuaciones arqueológicas en Cantabria (2004-2011) (G. Sanz Palomera, Ed.), Santander, 194-201.

Fischer, S., Graf, M.H., Fossurier, C., Châtelet, M. y Soulat, J. (2014), "An Inscribed Silver Spoon from Ichtratzheim (Bas-Rhin)", Journal of Archaeology and Ancient History, 11. [urn:nbn:se:uu:diva-218611]

García Guinea, M.A. (2006), "Broche de cinturón. Necrópolis de Santa María de Hito (Valderredible, Cantabria)", Apocalipsis. El ciclo histórico de Beato de Liébana (P.A. Fernández Vega, Ed.), Santander, 198.

García Guinea, M.A. (1999), "El marco cultural de los testimonios artísticos de Cantabria en la Edad Media”, I Encuentro de Historia de Cantabria, Santander, 523-552.

García Guinea, M.A. (1985), "Las excavaciones de 1981-1982”, Sautuola, IV, 207-229.

García Guinea, M.A. y Van den Eynde Ceruti, E. (1991), "Excavaciones arqueológicas en el yacimiento romano-medieval de Camesa-Rebolledo (Valdeolea, Cantabria)", Codex Aquilarensis, 4, 9-28.

Gilchrist, R. (2008), "Magic for the dead? The Archaeology of magic in later medieval burials", Medieval Archaeology, 52, 119-159.

Gimeno García-Lomas, R. (1978), "Hallazgo de un broche altomedieval trabajado en hueso", Boletín del Seminario de Arte y Arqueología, 44, 430-434.

Gimeno García-Lomas, R. (1986), "El conjunto de cerámicas medievales de Santa María de Hito”, Actas del I Congreso de Arqueología Medieval Española, V, Zaragoza, 385-401.
Gutiérrez Cuenca, E. (2002), “Dataciones absolutas para la Arqueología de época histórica en Cantabria”, Nivel Cero, 10, 89-111.

Gutiérrez Cuenca, E. (2015), Génesis y evolución del cementerio medieval en Cantabria, Santander, [hdl.handle.net/10803/311798]

Gutiérrez Cuenca, E. y Hierro Gárate, J.A. (2007), "Nuevas perspectivas para la reconstrucción histórica del tránsito entre la Antigüedad y la Alta Edad Media en Cantabria: la necrópolis de Santa María de Hito", Nivel Cero, 11, 97-116.

Gutiérrez Cuenca, E. y Hierro Gárate, J.A. (2009), "Dos anillos con inscripción procedentes de la necrópolis de Santa María de Hito (Cantabria)”, Pyrenae, 40/1, 149-173.

Gutiérrez Cuenca, E. y Hierro Gárate, J.A. (2012), "El uso de las cuevas naturales en Cantabria durante la Antigüedad Tardía y los inicios de la Edad Media (siglos V-X)”, Kobie. Paleoantropología, 31, 175-206.

Gutiérrez Cuenca, E. y Hierro Gárate, J.A. (2015), "Necrópolis y cuevas. Caracterización del registro funerario de los siglos VI-VIII en Cantabria”, Identidad y etnicidad en Hispania. Propuestas teóricas y cultura material en los siglos V-VIII (J.A. Quirós Castillo y S. Castellanos, Eds.), Vitoria, 201-219.

Halsall, G. (1995), Settlement and social organization. The Merovingian region of Metz, Cambridge.

La Rocca, C. (1998), "Donare, distribuire, spezzare. Pratiche di conservazione della memoria e dello status in Italia tra VIII e IX secolo", Sepolture tra IV e VIII secolo, VII Seminario sul Tardo Antico e l'Alto Medioevo in Italia Centro Settentrionale (G. Brogiolo y G. Cantino Wataghin, Eds.), Mantua, 77-87.

Larrea, J.J. (2016), "Las iglesias de los vascones: una problemática antigua y un registro arqueológico nuevo (siglos VI y VII)", Estudios sobre la Edad Media en el norte de la península ibérica (J.A. Fernández de Córdoba, Ed.), Oviedo, 221-248.

Lecanda, J.A. (2015), Estudio arqueológico del Desfiladero de La Horadada: La transición entre la tardorromanidad y la Alta Edad Media (ss.V-X d.n.e.), Burgos. [hdl.handle. net/10259/4641]

López Quiroga, J. (2010), Arqueología del mundo funerario en la Península Ibérica (siglos $V$-X), Madrid. 
Martin, M. (1988), “Bemerkungen zur frühmittelalterlichen Knochenschnalle eines Klerikergrabes der St. Verenakirche von Zurzach (Kt. Aargau)", Jahrbuch Der Schweizerischen Gesellschaft Für Ur- Und Frühgeschichte, 71, 161-177.

Martín Viso, I. (2014), "El espacio del más acá: las geografías funerarias entre la Alta y la Plena Edad Media", De la Tierra al Cielo. Ubi sunt qui ante nos in hoc mundo fuere? (E. López Ojeda, Ed.), Logroño, 75-140.

Martínez Santa-Olalla, J. (1933), Excavaciones en la necrópolis visigoda de Herrera de Pisuerga (Palencia), Madrid.

Meier, T. y Graham-Campbell, J. (2007), "Life, death and memory", The Archaeology of Medieval Europe. Vol. 1. Eigth to Twelfth Centuries $A D$ (J. Graham-Campbell y M. Valor, Eds.), Aarhus, 420-449.

Molinero Pérez, A. (1948), La necrópolis visigoda de Duratón (Segovia), Excavaciones del Plan Nacional de 1942 y 1943, Madrid.

Palol, P. (1986), "Las excavaciones del conjunto de 'El Bovalar', Serós (Segria, Lerida) y el Reino de Akhila”, Antigüedad y Cristianismo, 3, 513525.

Pérez González, C. (1985), "Capitel de Rebolledo (Valdeolea)", Sautuola, IV, 303-305.

Pinar, J. (2007), "Sepulturas 'góticas' y arquitectura en el Mediterráneo occidental, ca. 500 AD: una primera aproximación", Hortus Artium $\mathrm{Me}$ dievalium, 13/2, 271-290.

Pinar, J. y Turell, L. (2007), "Ornamenta vel vestimenta ex sepulchro abstulere. Reflexiones en torno a la presencia de tejidos, adornos y accesorios de indumentaria en el mundo funerario del Mediterráneo tardoantiguo", Collectanea Christiana Orientalia, 4, 127-167.

Quirós Castillo, J.A. y Vigil-Escalera Guirado, A. (2011), "Dove sono i visigoti? Cimiteri e villaggi nella Spagna centrale nei secoli VI e VII", Archeologia e storia delle migrazioni. Europa, Italia, Mediterraneo fra tarda etá romana e alto medioevo (C. Ebanista y M. Rotili, Eds.), Cimitile, 157-179.

Ripoll López, G. (1993), "Sarcófagos de la antigüedad tardia hispanica: importaciones y talleres locales", Antiquité Tardive, 1, 153-158.

Ripoll López, G. (1996), "La arquitectura funeraria de Hispania entre los siglos V y VIII: aproximación tipológica", Spania. Estudis d'Antiguitat Tardana oferts en homenatge al professor
Pere de Palol i Salellas, Barcelona, 215-224.

Salin, E. (1959), La civilisation mérovingienne d'après les sépultures, les textes et le laboratoire.Quatrième partie: Les Croyances. Conclusions. Index general, París.

Serna Gancedo, A., Valle Gómez, A. y Hierro Gárate, J. A. (2005), "Broches de cinturón visigodos y otros materiales tardoantiguos de la cueva de Las Penas (Mortera, Piélagos)", Sautuola, XI, 247-276.

Tejerizo García, C. (2011), "Ethnicity in early middle age cemeteries. The case of the 'visigothic' burials", Arqueología Y Territorio Medieval, 18, 29-43.

Treffort, C. (1996), L’église carolingienne et la mort: christianisme, rites funéraires et pratiques commémoratives, Lyon.

Van den Eynde Ceruti, E. (1985), "El tránsito a la Edad Media", In Historia de Cantabria. Prehistoria. Edades Antigua y Media (M.A. García Guinea, Ed.), Santander, 277-286.

Van den Eynde Ceruti, E. (2002), "Los niveles medievales del yacimiento de Camesa-Rebolledo. Apuntes sobre la más antigua ocupación medieval de Cantabria”, Sautuola, VIII, 261-296.

Van den Eynde, E. (1986), "Tipologías hispanovisigodas en yacimientos de la repoblación cantábrica”, Actas del I Congreso de Arqueología Medieval Española, II, 297-304.

Van den Eynde, E. y Illarregui, E. (1986), "Un ejemplo de integración de una necrópolis medieval sobre una estructura romana”, Arqueología Espacial, 10, 159-171.

Vigil-Escalera Guirado, A. (2009), "Las aldeas altomedievales madrileñas y su proceso formativo", The archaeology of early medieval villages in Europe (J.A. Quirós Castillo, Ed.), Bilbao, 315-339.

Werner, J. (1990), "Die beinschnalle von Villaverde de Hito (prov. Santander)", Kölner Jahrbuch Für Vor-Und Frühgeschichte, 23, 309-310.

Williams, H. (2010), "Engendered bodies and objects of memory in Final Phase graves", Burial in Later Anglo-Saxon England (J. Buckberry y A. Cherryson, Eds.), Oxford, 25-37. 
